\title{
John M. Rhee, Scott D. Boden, John M. Flynn EIC and Sam W. Wiesel: Operative techniques in spine surgery
}

\author{
2013, 435 pp, num. illustr. 260.00 US\$, Wolters Kluwer, Lippincott, Williams \& Wilkins, \\ Philadelphia, 2013; Philadelphia, Baltimore, New York, London, Buenos Aires, Hong \\ Kong, Sydney, Tokyo, ISBN 978-1-4511-2769-0
}

\author{
Pierre Kehr • Denis L. Kaech
}

Received: 26 March 2014/Accepted: 27 March 2014/Published online: 17 April 2014

(C) Springer-Verlag France 2014

This 423 pages textbook has been written by 90 contributors to 47 chapters and includes seven sections: one cervical, two thoracolumbar, three deformity, four complications, five intradural surgery, six paediatric spine, and seven approaches.

Every chapter has a "pearl and pitfall summary" giving practical tips for a successful surgery, what to do and what to avoid, repeating/stressing/highlighting/pointing again at the possibilities and limits of the described operative technique.

The chapters are didactically well written, defining step by step the relevant features of the described pathology, including anatomy, pathogenesis, natural history, history and physical findings, imaging and other studies, differential diagnosis, non-operative management and surgical management, indications, contraindications of a technique, followed by a description of the surgical steps with good illustrations. Then the postoperative care, the outcome and the complications are resumed. At the end of each chapter, the reader finds a list with up to 43 references.

Some shorter contributions focus on reduction techniques for $\mathrm{C}$-fractures and dislocations, with a treatment algorithm, on management of CSF leaks, and on intradural surgery. At the end, a 10 pages index allows to find quickly the chapters content of interest.

Richly illustrated with drawings of anatomy and various surgical techniques, describing classical orthopaedic and modern minimally invasive and microsurgical options, covering broadly spinal pathologies, this 2013 textbook is worth having and reading for every spine surgeon and should be in the library of every teaching institution department, as reference work for junior doctors.

Conflict of interest None.
P. Kehr $(\bowtie) \cdot$ D. L. Kaech AREDEJOST, Strasbourg, France

e-mail: kehrpier@aol.com 